Article

\title{
$\beta$-elimination of hyaluronate by red king crab hyaluronidase
}

\author{
Dmitrii Sliadovskii ${ }^{1}$, Tatyana Ponomareva ${ }^{1}$, Maxim Molchanov ${ }^{2}$, Ira Pozdnikova-Filatova ${ }^{3}$, Maria Timchenko ${ }^{1}$, Oleg \\ Gusev $^{4,5}$ and Evgeny Sogorin $1,+$ (i) \\ 1 Federal Research Center "Pushchino Scientific Center for Biological Research of the RAS", Pushchino, 142290, Russia \\ 2 Institute of Theoretical and Experimental Biophysics of the RAS, Pushchino, 142290, Russia \\ 3 Federal Research Center "Pushchino Scientific Center for Biological Research of the RAS", G.K. Skryabin Institute of \\ Biochemistry and Physiology of Microorganisms, Pushchino, 142290, Russia \\ 4 Extreme Biology Laboratory, Kazan Federal University, Kazan, 420012, Russia \\ 5 Department of Regulatory Transcriptomics for Medical Genetic Diagnostics, Juntendo University, Tokyo, 113-8421, \\ Japan \\ * Correspondence: evgenysogorin@gmail.com \\ + These authors contributed equally to this work.
}

\begin{abstract}
Crustacean hyaluronidases are poorly understood both in terms of their enzymatic properties and in terms of their structural features. In this work, we have shown that the hepatopancreas homogenate of the red king crab has a hyaluronidase activity that is an order of magnitude higher than its commercial counterpart. Zymography revealed the hyaluronidase activity of the protein roughly from 40 to $50 \mathrm{kDa}$ relative to the molecular marker used in electrophoresis. Analysis of the hepatopancreas transcriptome revealed a hyaluronidase sequence with an expected molecular weight of $42.5 \mathrm{kDa}$. It turned out that the reaction of cleavage of hyaluronate in the presence of a homogenate proceeds by the mechanism of $\beta$-elimination, which is well known for bacterial hyaluronidases. Thus, a new hyaluronidase of higher eukaryotes was found and described, which is not integrated into the modern classification of hyaluronidases.
\end{abstract}

Keywords: Hyaluronoglucosaminidase, Hyaluronidase, Hyaluronic Acid, Hyaluronate, Eukaryota, Hepatopancreas, Transcriptome, Crustacea, Bacteria, beta-elimination, NMR

\section{Introduction}

Hyaluronidases are a group of enzymes that can break down hyaluronate (HA). Most of them are also able to break down chondroitin and its derivatives [1]. Hyaluronidases are divided into three classes depending on the characteristics of their enzymatic activity [2]. Hyaluronate-4glycanohydrolases cleave the $\beta$ - $(1 \rightarrow 4)$-glycosidic bonds of the hyaluronate chain to form $\mathrm{N}$-acetylD-glucosamine at the reduced end of the oligosaccharides includung the hyaluronidases of mammals and some insects. Hyaluronate-3-glucanohydrolases of leech hyaluronidases hydrolyze $\beta$ - $(1 \rightarrow 3)$ glycosidic bonds. The reaction products contain $\mathrm{N}$-acetyl-D-glucosamine at the non-reduced end and D-glucuronic acid at the reduced end of the oligosaccharides. The third group-bacterial hyaluronate lyases - cleaves $\beta$ - $(1 \rightarrow 4)$-glycosidic bonds by the mechanism of $\beta$-elimination to form a double bond in D-glucuronic acid [3]. $\beta$-elimination of hyaluronate is usually identified only with bacterial hyaluronidases. However, the same type of hydrolysis was recently shown for the yeast Cryptococcus laurentii [4] and for the tinder fungus Fistulina hepatica [5] (Table 1).

The hyaluronidases of humans, some animals, and bacteria are well described both in terms of their biochemical properties and structural features [1,6,7]. However, crustacean hyaluronidases are poorly described. The hyaluronidase of langust Nephrops norvegicus having an optimum temperature of $45^{\circ} \mathrm{C}$ and a pH of 5.4 was characterized. According to the results of native gel filtration the molecular weight of the hyaluronidase is $320 \mathrm{kDa}$ [8]. The reaction mechanism of hyaluronate hydrolysis by langoustine hyaluronidase is still unknown. The hyaluronate-3-glycanohydrolase of Antarctic krill Euphausia superba [9] is described. According to the results of gel filtration, this hyaluronidase has a molecular weight of $80 \mathrm{kDa}$, the optimal $\mathrm{pH}$ is 5.3, the optimal temperature of the reaction mixture is $37^{\circ} \mathrm{C}$. To date, the amino acid sequence of langoustine and krill hyaluronidases is not known.

In the open UniProt protein sequence database, several amino acid sequences of hyaluronidases from other crustacean representatives can be found, namely from the Decapod order (Decapoda). 
These are the White-legged shrimp (Litopenaeus vannamei, UniProt A0A423SH46) and the Orange mud Crab (Scylla olivacea, two UniProt A0A0P4VVV1 and A0A0N7ZAX3), as well as two representatives of the order of Equipods (Isopoda): woodlouse Armadillidium vulgare (UniProt A0A444ST78) and Armadillidium nasatum (UniProt A0A5N5TJL6). However, the biochemical properties of these hyaluronidases have not been studied yet.

In our recent work, using turbidimetry, atomic force microscopy, and NMR spectroscopy, we showed the cleavage of the hyaluronate of the cosmetic filler under the influence of the hepatopancreas homogenate of the red king crab [10].

In the work, we identified the amino acid sequence of the red king crab hyaluronidase, and showed that the cleavage of hyaluronate follows the $\beta$-elimination mechanism.

Table 1. Some known hyaluronidases

\begin{tabular}{|c|c|c|c|}
\hline Hyaluronidase & $\begin{array}{l}\text { Opt. }{ }^{\circ} \mathrm{C} \text { and } \\
\text { pH }\end{array}$ & Substrate specificity & Additional information \\
\hline Testicular & $?, 5.0[11]$ & $\begin{array}{l}\text { HA, chondroitin, chondroitin } \\
\text { sulfate [12] }\end{array}$ & $\begin{array}{l}\text { hydrolysis at the } \beta-1,4-\text { glycosidic bond. Final product } \\
\text { is tetrasaccharide }[13] \text {. Capable of transglycosylation } \\
{[11,14]}\end{array}$ \\
\hline Leeches & $\begin{array}{l}45 \text { and } 6.5 \\
{[15]}\end{array}$ & $\begin{array}{l}\text { HA, does not hydrolyze chon- } \\
\text { droitin, chondroitin sulfate A } \\
\text { and C [16], and also does not } \\
\text { hydrolyze chitin and heparin } \\
\text { [15] }\end{array}$ & $\begin{array}{l}\text { hydrolysis at the } \beta-1,3 \text {-glycosidic bond, the final } \\
\text { product-hexa- and tetrasaccharide-contains glu- } \\
\text { curonic acid at the reduced end [15-17] }\end{array}$ \\
\hline $\begin{array}{l}\text { Streptomyces } \\
\text { hyalurolyticus }\end{array}$ & $\begin{array}{l}60 \text { and } 5.0 \\
{[13]}\end{array}$ & $\begin{array}{l}\text { HA, does not hydrolyze chon- } \\
\text { droitin and chondroitin sul- } \\
\text { fate, and also does not hy- } \\
\text { drolyze chitin, heparin, and } \\
\text { keratan sulfate [13] }\end{array}$ & $\begin{array}{l}\text { the reaction of } \beta \text {-elimination at the } \beta \text {-1,4-glycosidic } \\
\text { bond, hexa- and tetrasaccharide are the final products } \\
\text { of the endolytic activity of hydrolysis }[13,18,19]\end{array}$ \\
\hline Bacillus sp. A50 [20] & 44 and 6.5 & $\begin{array}{l}\text { HA, chondroitin sulfate } A, C \text {, } \\
\text { D }\end{array}$ & $\begin{array}{l}\text { the reaction of } \beta \text {-elimination at the } \beta-1,4 \text {-glycosidic } \\
\text { bond, the final product is a dimer }\end{array}$ \\
\hline $\begin{array}{l}\text { Cryptococcus lauren- } \\
\text { tii [4] (yeast) }\end{array}$ & 37 and 6.0 & $\mathrm{HA}, ?$ & $\begin{array}{l}\text { the reaction of } \beta \text {-elimination at the } \beta-1,4 \text {-glycosidic } \\
\text { bond, the final product is a dimer }\end{array}$ \\
\hline $\begin{array}{l}\text { Fistulina hepatica }[5] \\
\text { (filamentous fungi) }\end{array}$ & 20 and 4.0 & $\mathrm{HA}, ?$ & $\begin{array}{l}\text { the reaction of } \beta \text {-elimination at the } \beta \text {-1,4-glycosidic } \\
\text { bond, the final product is tetrasaccharide }\end{array}$ \\
\hline
\end{tabular}

\section{Materials and Methods}

\subsection{Materials}

Rooster crest hyaluronate (Sigma H5338) was used to detect the hyaluronidase activity.

The enzymatic preparation of the hepatopancreas of crab (HPC) was obtained as described earlier [10]. The lyase S. hyalurolyticus (Sigma H1136) was used. The hyaluronidase product "Lidazum" (Samson Med LLC, Russia) was of animal origin and was purchased at a pharmacy.

The leech head homogenate was prepared as previously described [21] with minor changes. 10 leech individuals Hirudo medicinalis (Giruda LLC, Russia) were used to obtain the preparation. The leeches were pre-frozen at $-70{ }^{\circ} \mathrm{C}$, then approximately $40-50 \%$ of the body was separated with a mouth sucker. Next, the leech head parts were placed in a mortar with liquid nitrogen and homogenized with a pestle to a state of powder. 50-200 $\mathrm{ml}$ of $0.15 \mathrm{M} \mathrm{NaCl}$ was added to the obtained material. $150-200 \mathrm{ml}$ of $0.15 \mathrm{M} \mathrm{NaCl}$ was added to the obtained material. The resulting mixture was being extracted overnight at a temperature of $4{ }^{\circ} \mathrm{C}$. The next day, the solution was centrifuged for 15 minutes at $1500 \mathrm{~g}$ at a temperature of $4{ }^{\circ} \mathrm{C}$. The supernatant was gradually mixed with ammonium sulfate to a final concentration of $70 \%$ of the saturated. The mixture was then centrifuged again for 
15 minutes at 1500 and $4{ }^{\circ} \mathrm{C}$, after which the precipitate was dissolved in $5 \mathrm{ml} 0.1 \mathrm{M}$ sodium acetate, $\mathrm{pH}$ 6, and dialyzed against deionized water overnight at $4{ }^{\circ} \mathrm{C}$.

\subsection{Methods}

\subsubsection{Enzymatic activity measurement}

The HA solution was preheated at the reaction temperature. Then an enzyme preparation was added to the substrate, the reaction mixture was pipetted and incubated. After that, the minitubes with the reaction mixture were placed in a boiling water bath to stop the reaction. In the reaction mixtures, 82-164 IU per $1 \mathrm{mg}$ of HA were used. In the case of leech head homogenate, a ratio of enzyme preparation to HA was used equal to 1 (volume) to 8-16 (by weight). The reaction mixtures were incubated either at $42{ }^{\circ} \mathrm{C}$ (for lyase $S$. hyalurolyticus), or at $37-38{ }^{\circ} \mathrm{C}$ (for the rest).

To determine the hyaluronidase activity using the Morgan-Elson reaction [22,23], the reaction mixture was cooled to room temperature after thermal inactivation. A $1 \mathrm{M}$ solution of potassium tetraborate was added to it. After that, the samples were immediately placed onto a boiling water bath for 3 minutes. Then the samples were cooled again to room temperature, and an Ehrlich reagent containing $0.67 \mathrm{M}$ p-dimethylaminobenzaldehyde dissolved in acetic acid and containing $12 \%$ hydrochloric acid was added to the samples. After adding the Ehrlich reagent, the mixture was placed in a thermostat and incubated for 20 minutes at $38^{\circ} \mathrm{C}$. After that, the absorption was measured at a wavelength of $540 \mathrm{~nm}$ on a Multiscan Fc (Thermo Fisher Scientific) plate reader.

Turbidimetry of reaction mixtures of HA hydrolysis using leech head homogenate was performed as described earlier [10].

The HA $\beta$-elimination reaction was detected by measuring the absorption at a wavelength of $232 \mathrm{~nm}$ every $10 \mathrm{~s}$ of incubation of the reaction on a thermostated spectrophotometer Varian Cary 100 Bio Spectrophotometer. A solution of HA $(150 \mu \mathrm{L}, 2 \mathrm{mg} / \mathrm{ml}$ or $1 \mathrm{mg} / \mathrm{ml} \mathrm{HA}$, in phosphate buffer, pH 6, containing $162 \mathrm{mM}$ sodium hydrogen phosphate) was placed in a cuvette and heated for $5 \mathrm{~min}$ at the reaction temperature. Next, an enzymatic preparation was added and vigorously mixed. HA in phosphate buffer without the addition of an enzyme preparation was used as a reference solution.

Zymography of hyaluronidases was performed in $10 \%$ polyacrylamide gel under denaturing conditions as described earlier with minor changes [24]. Before application, the sample was mixed with a loading buffer (62.5 mM Tris, $100 \mathrm{mM}$ DTT, $0.02 \%$ bromophenol blue, $10 \%$ glycerin, $0.2 \%$ SDS) in a ratio of 1 to 5 by volume, respectively. $2.5 \mu \mathrm{g}$ of total protein was applied to the well. The concentrating $3.75 \%$ gel contained $0.5 \mathrm{M}$ Tris- $\mathrm{HCl}$ (pH 6.8), $1 \%$ SDS. $0.05 \%$ ammonium persulfate and $0.01 \%$ TEMED were used for polymerization. The separating $10 \%$ gel contained $1.5 \mathrm{M}$ Tris- $\mathrm{HCl}$ (pH 8.8), 1\% SDS, $0.2 \mathrm{mg} / \mathrm{ml}$ of hyaluronate (Sigma H5338) dissolved in bidistillate, as a substrate. $0.05 \%$ ammonium persulfate and $0.01 \%$ TEMED were used for polymerization. Electrophoretic separation was performed in a Tris-HCl-Glycine-SDS buffer containing 0.25 M Tris-HCl, 0.192 $\mathrm{M}$ glycine, $0.1 \% \mathrm{SDS}, \mathrm{pH} 9$, at $4{ }^{\circ} \mathrm{C}, 50 \mathrm{~mA}$, and $125 \mathrm{~V}$ for 4.5 hours. After separation, the gel was washed with deionized water, then placed in a buffer containing 0.05 M HEPES and 3\% Triton X100 for 1 hour to remove SDS from the gel. After that, they were washed with deionized water and rinsed twice in a buffer containing 0.05 $\mathrm{M}$ HEPES and $0.15 \mathrm{M} \mathrm{NaCl}$. Next, the gel was placed in an incubation buffer containing $0.15 \mathrm{M} \mathrm{NaCl}$ and $0.1 \mathrm{M} \mathrm{HCOONa}, \mathrm{pH} 3.7$ (adjusted with $\mathrm{HCOOH}$ ) at $37{ }^{\circ} \mathrm{C}$, for 16 hours. After that, the gel was stained for 1 hour in $1 \%$ alcyan blue, dissolved in $3 \%$ acetic acid. The gel was washed with a mixture of $7 \%$ acetic acid and $10 \%$ ethyl alcohol in two shifts of 1 hour each.

2.2.2. Transcriptome analysis of red king crab hepatopancreas and cloning of the coding sequence of the hyaluronidase gene

The de-novo transcriptome assembly approach was used to search for the sequence of mature crab hyaluronidase mRNA. To assemble the transcripts, we used sequencing data on the Illumina HiSeq2500 platform of adult crabs and separately hepatopancreas (SRA NCBI: SRX5509375; SRX5509376; SRX5509377; SRX5509378) with a total volume of more than 13 GBase. Using the CLC Genomics Workbench (Quiagen) software, transcripts were assembled de-novo. Then, based on a sample of known insect hyaluronidase sequences and candidates, a candidate RNA carrying the full-length coding sequence of the gene was identified. Based on the mRNA sequence data, specific 
primers Hyal_F (ATGCCAAAGTTCCAGTTGAGC) and Hyal_R (TTATTTATCTTTCCCTGTGTGAG) were developed.

For cloning, total RNA from the hepatopancreas tissue of the red king crab was isolated using an ExtractRNA kit (Eurogen, Russia) according to the manufacturer's protocol. For the synthesis of the first DNA chain, Maxima H Minus First Strand cDNA Synthesis Kit (Thermo Fisher Scientific, USA) and oligo(dT)18 were used. Subsequent amplification was performed using Encyclo polymerase (Eurogen, Russia) and specific primers Hyal_F and Hyal_F. Amplicons were cloned in the pGEM-T Easy plasmid vector (Promega, USA), and the hyaluronidase sequence was confirmed by sequencing.

\subsubsection{NMR spectroscopy of HA cleavage products}

One-dimensional (1D) ${ }^{1} \mathrm{H}-\mathrm{NMR}$ spectra were acquired with a Bruker Avance III 600 spectrometer (The Core Facilities Centre of Institute of Theoretical and Experimental Biophysics of the RAS) operating at a frequency of $600 \mathrm{MHz}(1 \mathrm{H})$ and a probe temperature of $311 \mathrm{~K}$ or $315 \mathrm{~K}$ as described earlier [10].

\section{Results}

3.1. Cleavage of hyaluronate at the $\beta-(1 \rightarrow 4)$-glycosidic bond in the presence of HPC homogenate

The enzymatic activity of the red king crab hypatopancreas homogenate was determined using a colorimetric method based on the Morgan-Elson reaction [22,23]. The method is based on the chromogen formation (a colorable reaction product). When $\mathrm{N}$-acetyl-D-glucosamine is heated under alkaline conditions, it forms furan derivatives that react with $p$-dimethylaminobenzaldehyde to form a red dye, which is detected spectrophotometrically - the higher the color intensity, the greater the reaction product with $\mathrm{N}$-acetyl-D-glucosamine at the reduced end of the chain.

The commercial drug "Lydazum" was used as a standard sample [25] to determine the hyaluronidase activity. The cleavage of HA with HPC homogenate was performed under the found optimal conditions (Appendix A Figure 1). It turned out that the hyaluronidase activity of the HPC homogenate exceeds the commercial drug by several times based on the amount of the total protein of the drug in the reaction mixture (Figure 1). Detection of the colored product indicates cleavage of HA by the $\beta$-1,4-glycosidic chain bond in the presence of the enzyme preparation HPC homogenate. The colored product is not observed in the case of leech hyaluronidase [15] or Antarctic krill Euphausia superba [9]. The leech and Antarctic krill hyaluronidases hydrolyze HA by $\beta$ - $(1 \rightarrow 3)$-glycosidic bond to produce $\mathrm{N}$-acetyl-D-glucosamine at the non-reduced end of the reaction products, which is not able to enter the Morgan-Elson reaction.

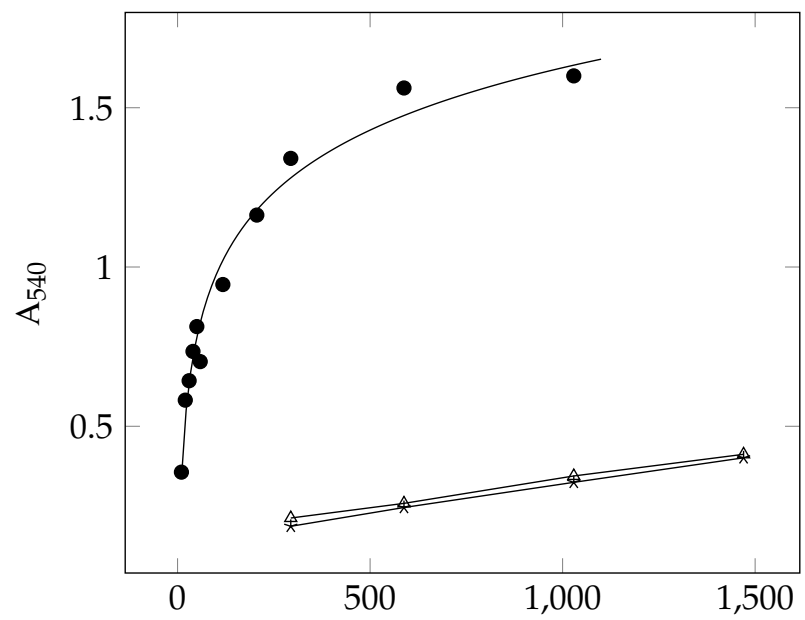

The amount of total protein of the enzyme preparation in the reaction mixture, $\mu \mathrm{g}$

Figure 1. The rate of accumulation of the products of the HA cleavage reaction using the HPC homogenate and the commercial preparation "Lydazum" depending on the amount of the total protein of the preparation in the reaction mixture, incubation at $38{ }^{\circ} \mathrm{C}, 20$ min, in an acetate buffer (pH 5.62): • HPC homogenate, $\triangle$ preparation "Lydazum", — preparation "Lydazum" (repeat). 


\subsection{Zymography}

Zymography of the HPC homogenate revealed the hyaluronidase activity of the protein roughly from 40 to $50 \mathrm{kDa}$ relative to the molecular marker used in electrophoresis. In addition, it was found that heating the HPC homogenate preparation in the buffer for applying the sample to the gel (in the presence of DTT or in its absence) leads to an irreversible loss of hyaluronidase activity (Figure 2(a)). This is not observed in the case of activity detection by zymography of actinobacterium hyaluronidase Streptomyces hyalurolyticus - the enzyme retains its activity after heating in the buffer, but the presence of DTT in it prevents the formation of aggregates after heating (Figure 2(b)). According to the marker, the molecular weight of hyaluronidase $S$. hyalurolyticus is in the range of 15 to $25 \mathrm{kDa}$, which is close to lyase $S$. koganeiensis $(21.6 \mathrm{kDa}$ ) [26,27]. It should be noted that the molecular weight of hyaluronidase $S$. hyalurolyticus declared by the manufacturer is $91 \mathrm{kDa}$, which was determined by the results of gel filtration. Such a large difference can be explained by the oligomerization of hyaluronidase $S$. hyalurolyticus under gel-filtration conditions.

The loss of the hyaluronidase activity after heating may be associated with irreversible thermal denaturation of the hyaluronidase, or with the activation of proteolytic enzymes of the HPC homogenate at high temperatures during heating. In this case, it must be assumed that the presence of a detergent at a concentration of $0.2 \%$ (SDS) in the buffer did not radically affect the activity of some proteolytic enzyme of the HPC homogenate. It is also necessary to note the wide extension of the band of hyaluronidase activity of the HPC homogenate in the substrate gel. This is probably due to the influence of post-translational modifications (glycosylation reduces the electrophoretic mobility of the protein). Thus, it was shown that the deglycosylation of the sperm membrane hyaluronidase ( $\mathrm{PH}-20$ protein) leads to an increase in its electrophoretic mobility in the gel [28]. Mobility of recombinant bee hyaluronidase Apis mellifera isolated from E. coli and not containing glycosylated sites, also differed in mobility from the native protein [29]. Thus, the observed wide band of activity in the gel may be due to the glycosylation of hyaluronidase molecules in the homogenate, which leads to a spread in electrophoretic mobility.

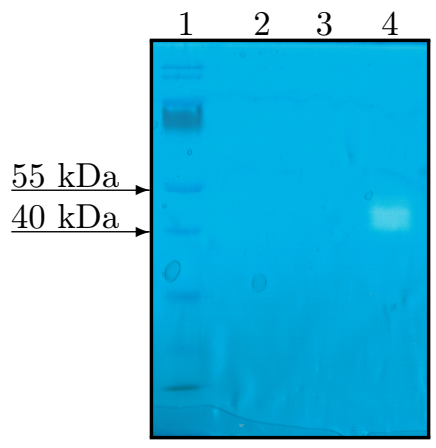

(a)

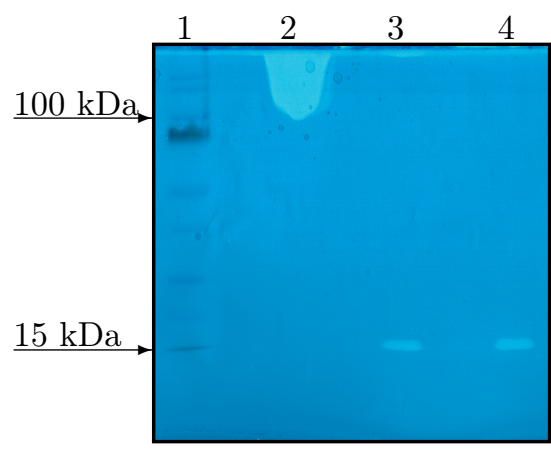

(b)

Figure 2. Zymogram in polyacrylamide gel containing hyaluronate as a substrate: (a)—HPC homogenate (1—protein marker, 2 homogenate after heating in the buffer for application to the gel, 3-homogenate after heating in the buffer for application without DTT, 4-homogenate in buffer with DTT without warming up), (b)—actinobacteria hyaluronidase S. hyalurolyticus (1—protein marker, 2-hyaluronidase after warming up in buffer without DTT, 3-hyaluronidase after warming up in buffer with DTT, 4-hyaluronidase in buffer with DTT without warming up). Protein marker PageRuler ${ }^{\mathrm{TM}}$ Prestained Protein Ladder: 180, 130, 100, 70, 55, 40, 35, 25, 15, 10 $\mathrm{kDa}$. The samples were being heated in the buffer for application for 5 minutes at $95{ }^{\circ} \mathrm{C}$.

\subsection{Formation of a double bond during the $\beta$-elimination of hyaluronate in the presence of HPC homogenate}

The formation of a double bond between C-4 and C-5 glucuronic acid atoms during the $\beta$ elimination of HA makes it possible to detect the kinetics of the in situ reaction by measuring the absorption of UV radiation during incubation of the reaction mixture (Figure 3). As a positive control, the lyase $S$. hyalurolyticus was used, in the presence of which an increase in light absorption 
was observed in the reaction mixture at a wavelength of $232 \mathrm{~nm}$, which indicates the formation of a double bond during the cleavage of HA by the $\beta$-elimination reaction. As a negative control, the preparation of testicular hyaluronidase ("Lydazum") and leech head homogenate (Section 2) were used. As expected, both of these hyaluronidases did not lead to an increase in the UV absorption of the reaction mixture, despite their hydrolysis of HA, which is detected by other methods under the same conditions (Appendix A Figure 2). Incubation of HPC homogenate in a phosphate buffer without HA in the mixture also did not lead to an increase in absorption at a wavelength of 232 $\mathrm{nm}$. Immediately after the addition of the HPC homogenate to the HA solution, an increase in the absorption of UV radiation was observed, which indicates the cleavage of HA by the homogenate enzymes by the $\beta$-elimination mechanism, as in the case of bacterial lyase.

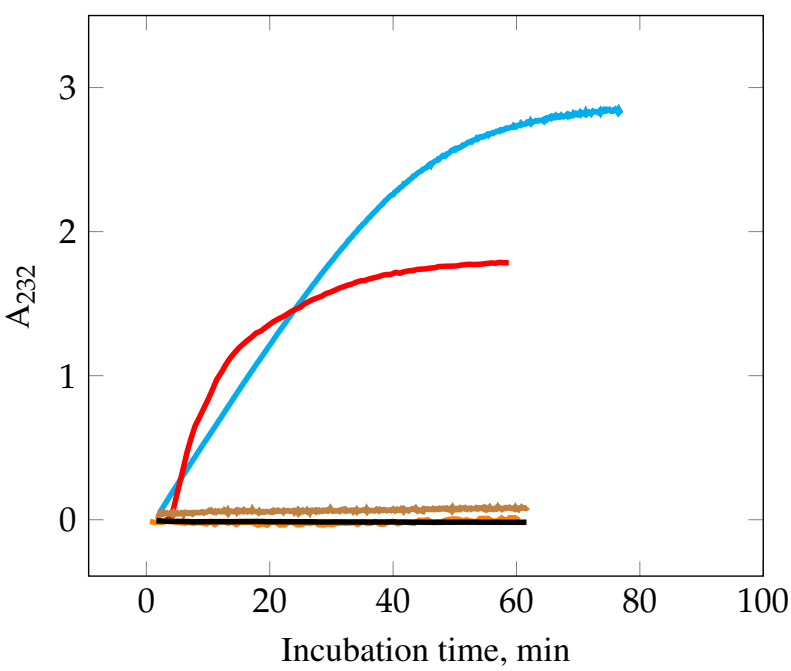

Figure 3. In situ-monitoring of the double bond formation during the $\beta$-elimination reaction of HA (in the phosphate buffer, $\mathrm{pH}$ 6): —_ lyase S. hyalurolyticus, — HPC homogenate, — «ydazum», — HPC homogenate without HA, — leech head homogenate.

\subsection{HPC transcriptome analysis and cloning of the hyaluronidase gene}

De-novo assembling the transcriptome allowed us to create a database consisting of 101,101 contigues, reflecting the totality of transcripts of the red king crab. The length of the transcripts varied from $200 \mathrm{bp}$ to $20,595 \mathrm{bp}$, with an average length of $720 \mathrm{bp}$. Then, from the obtained transcripts, we created a local BLAST database and identified a potential gene for the red king crab hyaluronidase based on the similarity with the known arthropod hyaluronidase genes. The transcript containing the coding part of hyaluronidase consisted of $1628 \mathrm{bp}$, and contained an open reading frame with a length of $1119 \mathrm{bp}$, encoding a protein of 372 amino acids. The primary amino acid sequence of the identified gene was closest to shrimp hyaluronidase Penaeus vannamei: (Score $=375.9$ bits (964), Expect $=3$ E-125, Identities $=172 / 313(54 \%)$, Positives $=224 / 313(72 \%)$, Gaps $=3 / 313(1 \%)$ (BLAST database).

To clone cDNA hyaluronidase, a total HPC RNA preparation was obtained. Single-stranded DNA of all polyadenylated mRNAs was produced using oligo (dT)18-primer. After that, PCR was performed using oligonucleotides specific to the hyaluronidase gene, the sequence of which corresponded to the transcriptome analysis data. The exception is the position of the amino acid Tyr193, in the codon of which there was an insignificant replacement: UAC (cloning) $\rightarrow$ UAU (transcriptome). The resulting plasmid construct will then be used to produce an expression system.

\subsection{Analysis of HA hydrolysis products by ${ }^{1} H-N M R$ spectroscopy}

NMR spectroscopy has previously been used to analyze reaction products and study the kinetics of the HA cleavage reaction [10,19,30-32]. As shown, the cleavage of HA by the enzymes of the HPC homogenate leads to an increase in the signal of the protons of the acetyl group of N-acetyl-Dglucosamine in the HA and the appearance of two peaks in the range 2.08-2.02 ppm [10], one of 
which corresponds to the signal of the protons of the acetyl group of $\mathrm{N}$-acetyl-D-glucosamine inside the HA chain, and the other signal of the protons of the acetyl groups of N-acetyl-D-glucosamine, which is formed at the ends of the HA fragments during cleavage.

In this work, the process of HA cleavage by lyase S. hyalurolyticus, HPC homogenate and leech head homogenate was studied. In the case of HPC homogenate and bacterial lyase, two peaks were observed at 2.032 and $2.074 \mathrm{ppm}$, corresponding to the signals of the protons of the N-acetyl-Dglucosamine acetyl groups located inside the chain and at the ends of HA fragments (Figure 4(a)). The HA hydrolysis by leech head homogenate results in the appearance of these two peaks roughly from 2.032 and $2.059 \mathrm{ppm}$. This is probably due to the location of N-acetyl-D-glucosamine at the non-reduced end of the HA chains in the case of hydrolysis by leech hyaluronidase, which cleaves the HA by the $\beta$ - $(1 \rightarrow 3)$-glycosidic bond.

It is known that the chemical shift of the H-4 proton at the double bond of unsaturated oligoglucuronates is in the down-field region [33]. As expected, the ${ }^{1} \mathrm{H}-\mathrm{NMR}$ spectroscopy analysis of the reaction mixture of HA hydrolysis in the presence of leech head homogenate enzymes did not show signals in this region (Figure 4(b)). In the case of HA cleavage by lyase S. hyalurolyticus and HPC homogenate, a proton signal in the down-field region is detected in the spectrum (5.865 ppm). This confirms that HPC hyaluronidase as well as bacterial lyase cleaves HA by the mechanism of $\beta$-elimination with the formation of a double bond.

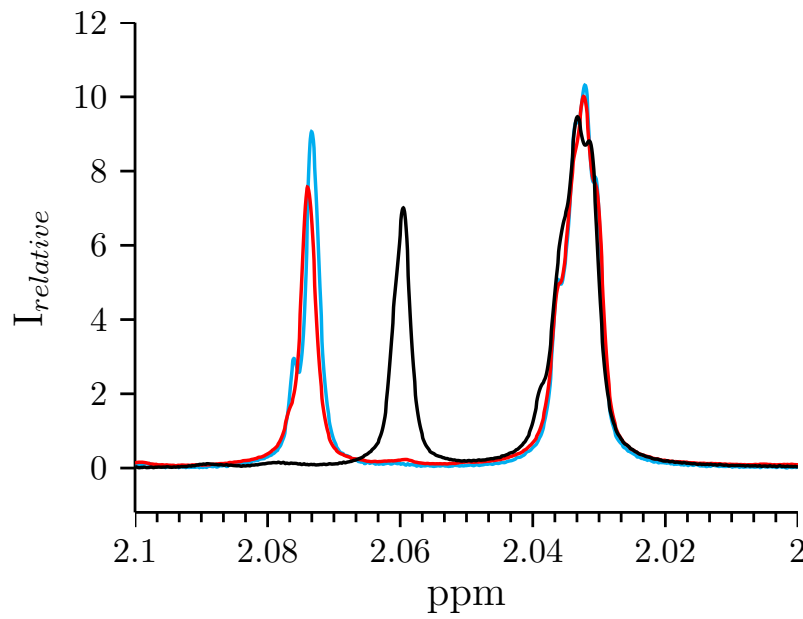

(a)

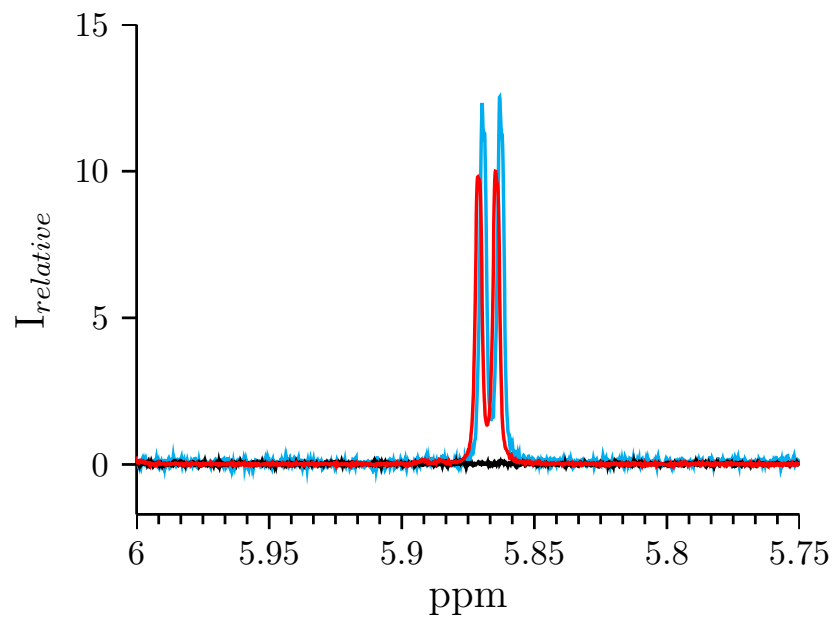

(b)

Figure 4. ${ }^{1} \mathrm{H}-\mathrm{NMR}$ spectra of the hydrolysis products after treatment by: —— lyase S. hyalurolyticus, — HPC homogenate, — leech head homogenate. (a) — the signal of protons of $\mathrm{N}$-acetyl-D-glucosamine acetyl group of HA chains, (b) - the ${ }^{1} \mathrm{H}$ signal of protons at double link in $\Delta^{4,5}$-unsaturated glucuronic acid residue.

\subsection{Search for homologues of the identified amino acid sequence of red king crab hyaluronidase}

The SwissProt database contains the amino acid sequences of the following enzymes that can use HA as a substrate (date of reference to the database is 06.06.2021):

- $\quad$ EC 3.2.1.35 (catalyzes the breaking of the $\beta$ - $(1 \rightarrow 4)$ bond) -61 representatives, of which 2 of them are found in bacteriophages of microorganisms of the genus Streptococcus (P15316 and Q54699), and 59 representatives are found in organisms of the kingdom Animalia (classes Insecta, Arachnida, Reptilia, Mammalia, as well as Gastropoda (genus Conus)).

- $\quad$ EC 3.2.1.36 (catalyzes the breaking of the $\beta$ - $(1 \rightarrow 3)$ bond) -1 representative, found in Hirudo nipponia (Korean blood-sucking leech) (X4Y2L4).

- $\quad$ EC 4.2.2.1 (catalyzes the breaking of the $\beta$ - $(1 \rightarrow 4)$ bond, $\beta$-elimination) -9 representatives (7 of them are found in bacteria and 2 in Homo sapiens), 3 of them (Q12794 (Homo sapiens), Q12891 (Homo sapiens) and P26831 (Clostridium perfringens)) also apply to EC 4.2.2.1 and EC 3.2.1.35. 
The red king crab hyaluronidase has a length of 372 amino acid residues (Appendix Figure 3), a molecular weight of $42.5 \mathrm{kDa}$, and is the first hyaluronidase described for the class Malacostraca. Among the orthologs detected by BLASTP in the SwissProt database there are hyaluronidases of the class 3.2.1.35 (including Q12794 (Homo sapiens), and Q12891 (Homo sapiens)). At the same time, the hyaluronidase of the red king crab is not included in any of the clades formed by known representatives of this class (Figure 5).

Tree scale: 1

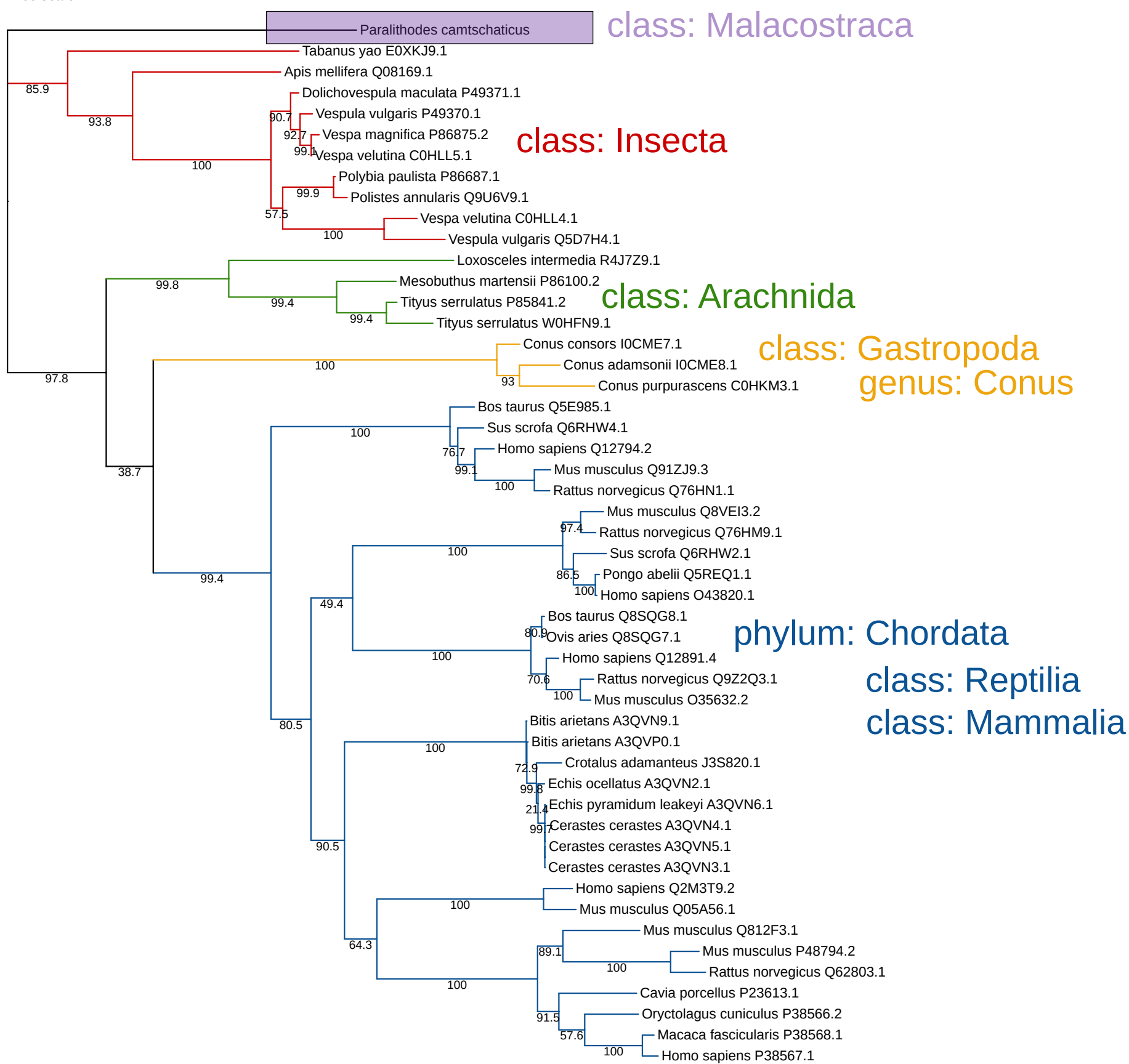

Figure 5. Phylogenetic tree of the homologues of the red king crab hyaluronidase, constructed on the basis of the Swiss-Prot database. Homologues were searched in the Swiss-Prot database using BLASTP with default parameters. A phylogenetic tree was constructed from MUSCLE-aligned sequences of hyaluronidases with the help of IQ-TREE [34]. For visualization, iTOL was used [35], bootstrap values are indicated at the branch points. 


\section{Discussion}

To date, hyaluronidases have been widely used in various fields of medicine: in local anesthesia [36,37], in ophthalmology [38,39], in dermatosurgery [40]. According to market research, about $65 \%$ of the medications are animal-derived hyaluronidases, the rest are recombinant forms of [41]. A significant part of the preparations of animal origin-homogenates of animal testicular tissues (for example, "Lydazum", "Liporaza" and others). However, the arsenal of potential drugs of medical value hyaluronidases continues to be replenished with new sources.

In this work, we have shown that the rate of cleavage of hyaluronate is several times higher than the rate of hydrolysis by a commercial analog ("Lydazum") based on the total protein in the studied preparations of hyaluronidase. Since the hepatopancreas of the red king crab is a waste product of crab processing, and also taking into account the volumes of catch in different countries, we can safely talk about industrial volumes of hepatopacreas as a raw material for obtaining a new potential medical drug hyaluronidase [42].

In the future, it is necessary to study the substrate specificity of the identified red king crab hyaluronidase and other biochemical properties of the homogeneous hyaluronidase preparation obtained either from the homogenate or its recombinant form.

The most unexpected thing in this work is the detection of HA cleavage by the mechanism of $\beta$-elimination by the red king crab hyaluronidase. Traditionally, this mechanism of cleavage is identified only with the "bacterial" type of hyaluronidases. Along with the hyaluronidases of some yeasts and fungi, the red king crab hyaluronidase brings us closer to the moment of rethinking the classification of hyaluronidases by the mechanism of HA cleavage. It is likely that this mechanism of cleavage of hyaluronate is more widespread in nature than is currently declared.

Author Contributions: Conceptualization, T.P. and E.S.; methodology, D.S., M.M., I.P.-F., O.G.; software, M.M., I.P.-F., O.G.; investigation, D.S., M.M., I.P.-F., O.G.; resources, T.P.; data curation, E.S.; writingoriginal draft preparation, E.S.; writing-review and editing, T.P., M.T.; visualization, E.S., I.P.-F.; supervision, E.S.; project administration, E.S. All authors have read and agreed to the published version of the manuscript.

Funding: This research received no external funding.

Institutional Review Board Statement: Not applicable.

Informed Consent Statement: Not applicable.

Acknowledgments: We thank Sergey Lapaev for help in preparing the text and Nikika Pozdnyakov and Azat Abdulatypov for discussing the results.

Conflicts of Interest: The authors declare no conflict of interest. The funders had no role in the design of the study; in the collection, analyses, or interpretation of data; in the writing of the manuscript, or in the decision to publish the results.

\section{Abbreviations}

The following abbreviations are used in this manuscript:

HPC HepatoPancreas of a Crab

\section{Appendix A}




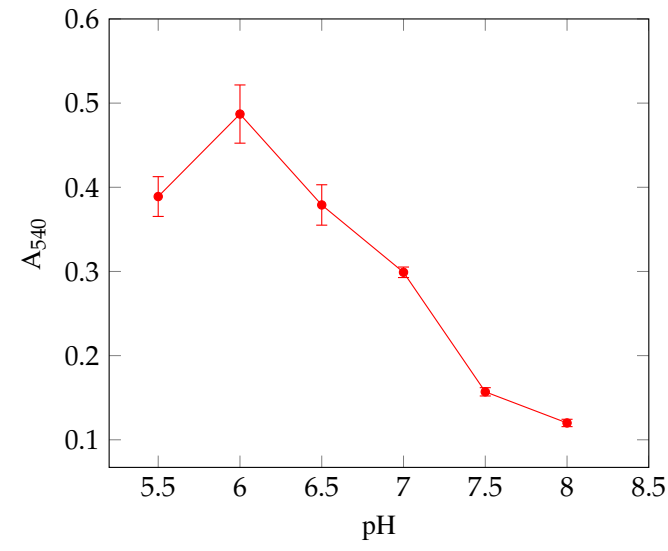

(a)

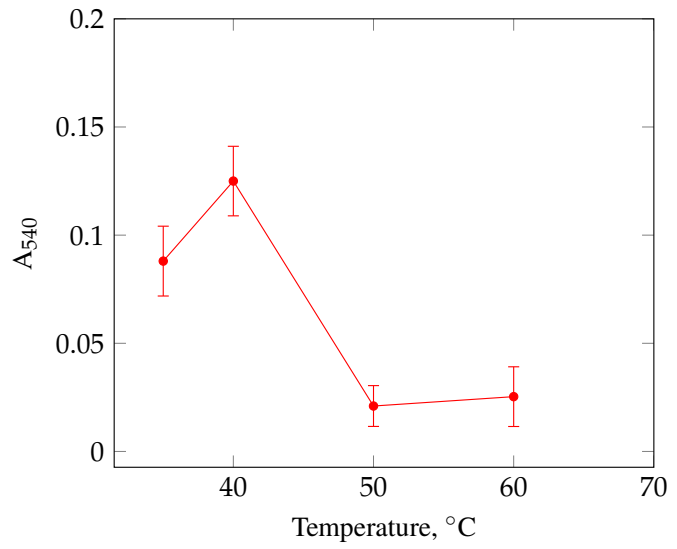

(b)

Figure 1. Cleavage of hyaluronate by HPC homogenate (detection by the Morgan-Elson reaction): (a) in different values of the acidity of the phosphate buffer, (b) at different reaction temperatures.

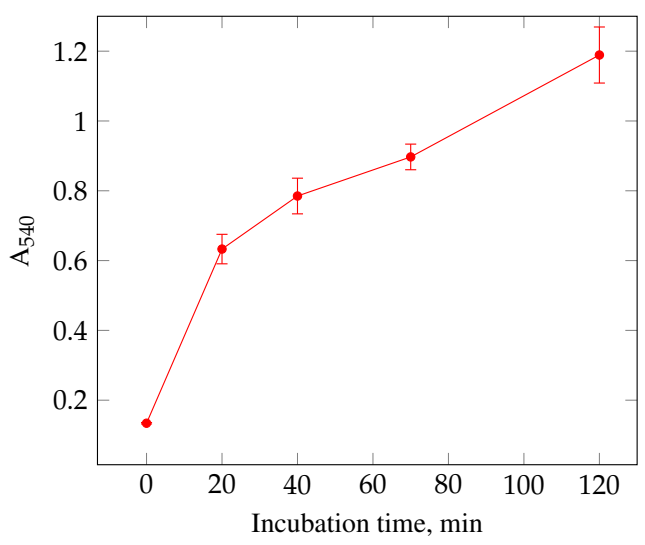

(a)

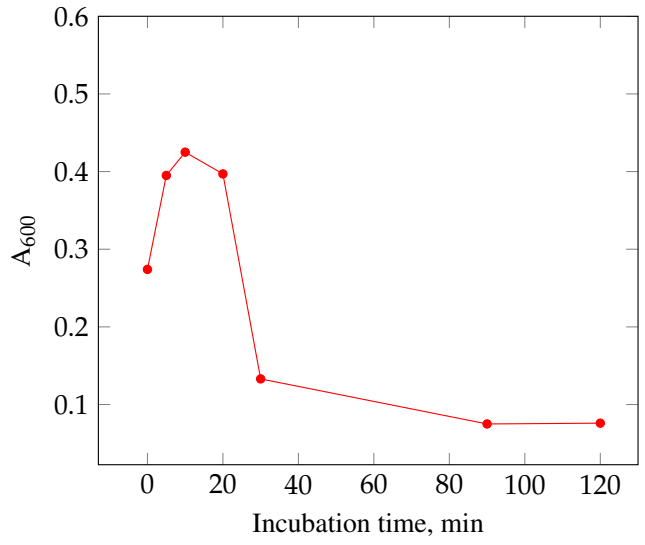

(b)

Figure 2. Hydrolysis of hyaluronate: (a) using the "Lydazum" drug (detection by the Morgan-Elson reaction), (b) using leech head homogenate (turbidimetric analysis). 


\title{
MPKFQLSQVCLCVVLWSLLSVTSGFNVYWNVPSYLCSKFGIHVNVSKFGIVQN
}

\author{
ANDRFYGDKVNIFYKHGLFPTLNRDGSVRANGGIPQKGNLTAHISTFTHRVKA
}

QLPHNYTGLAVLDFESYYPSFDMSPPEYRDASRSWVSSLHPKWPGWKVEDEARR

TFNNSAREFFQVLLQVGRELCPGAQWGYYHYPYCHNYQPSITHCQPPVQDHNDA

SLWLIQDSGALYPSIYISENSGWSPRARRLQARVRLGEAVRMAYVAHTPHTPIL

PYFWYRYHDSKERLSSLDLVNTLGLVRMMGLAGAVVWGSSSDLASHDQCLQFKS

YAEDKLGPLVRYLQELPLSSLPRLLRSHRRLRSFVTSALTTSPSHTGKDK*

Figure 3. Amino acid sequence of red king crab hyaluronidase

\section{References}

1. $\quad$ Wang, W.; Wang, J.; Li, F. Hyaluronidase and chondroitinase. Protein Reviews 2016, pp. 75-87.

2. Meyer, K. Hyaluronidases. In The enzymes; Elsevier, 1971; Vol. 5, pp. 307-320.

3. Linker, A.; Meyer, K.; Hoffman, P. The production of unsaturated uronides by bacterial hyaluronidases. Journal of Biological Chemistry 1956, $219,13-25$.

4. Smirnou, D.; Krčmář, M.; Kulhánek, J.; Hermannová, M.; Bobková, L.; Franke, L.; Pepeliaev, S.; Velebnỳ, V. Characterization of hyaluronandegrading enzymes from yeasts. Applied biochemistry and biotechnology 2015, 177, 700-712.

5. Bobkova, L.; Smirnou, D.; Krcmar, M.; Kulhanek, J.; Hermannova, M.; Franke, L.; Velebny, V. Discovery and Characteristic of Hyaluronidases from Filamentous Fungi. Current Biotechnology 2018, 7, 2-9.

6. Stern, R.; Jedrzejas, M.J. Hyaluronidases: their genomics, structures, and mechanisms of action. Chemical reviews 2006, 106, 818-839.

7. Tsepilov, R.; Beloded, A. Hyaluronic acid—an "old" molecule with "new" functions: biosynthesis and depolymerization of hyaluronic acid in bacteria and vertebrate tissues including during carcinogenesis. Biochemistry (Moscow) 2015, 80, 1093-1108.

8. Krishnapillai, A.M.; Taylor, K.A.; Morris, A.E.; Quantick, P.C. Characterisation of Norway lobster (Nephrops norvegicus) hyaluronidase and comparison with sheep and bovine testicular hyaluronidase. Food chemistry 1999, 65, 515-521.

9. Karlstam, B.; Ljunglöf, A. Purification and partial characterization of a novel hyaluronic acid-degrading enzyme from Antarctic krill (Euphausia superba). Polar Biology 1991, 11, 501-507.

10. Ponomareva, T.; Sliadovskii, D.; Timchenko, M.; Molchanov, M.; Timchenko, A.; Sogorin, E. The effect of hepatopancreas homogenate of the Red king crab on HA-based filler. PeerJ 2020, 8, e8579.

11. Saitoh, H.; Takagaki, K.; Majima, M.; Nakamura, T.; Matsuki, A.; Kasai, M.; Narita, H.; Endo, M. Enzymic reconstruction of glycosaminoglycan oligosaccharide chains using the transglycosylation reaction of bovine testicular hyaluronidase. Journal of Biological Chemistry 1995, $270,3741-3747$.

12. Davidson, E.A.; Meyer, K. Chondroitin, a new mucopolysaccharide. Journal of Biological Chemistry 1954, $211,605-611$.

13. Ohya, T.; Kaneko, Y. Novel hyaluronidase from streptomyces. Biochimica et Biophysica Acta (BBA) - Enzymology 1970, $198,607-609$. doi:https://doi.org/10.1016/0005-2744(70)90139-7.

14. Weissmann, B. The transglycosylative action of testicular hyaluronidase. Journal of Biological Chemistry 1955, 216, 783-794.

15. Jin, P.; Kang, Z.; Zhang, N.; Du, G.; Chen, J. High-yield novel leech hyaluronidase to expedite the preparation of specific hyaluronan oligomers. Scientific reports 2014, 4, 1-8.

16. Linker, A.; Meyer, K.; Hoffman, P. The production of hyaluronate oligosaccharides by leech hyaluronidase and alkali. Journal of Biological Chemistry 1960, 235, 924-927.

17. Linker, A.; Hoffman, P.; Meyer, K. The hyaluronidase of the leech: an endoglucuronidase. Nature 1957, 180, 810-811.

18. Shimada, E.; Matsumura, G. Degradation process of hyaluronic acid by Streptomyces hyaluronidase. The Journal of Biochemistry 1980, $88,1015-1023$.

19. Park, Y.; Cho, S.; Linhardt, R.J. Exploration of the action pattern of Streptomyces hyaluronate lyase using high-resolution capillary electrophoresis. Biochimica et Biophysica Acta (BBA)-Protein Structure and Molecular Enzymology 1997, 1337, $217-226$.

20. Guo, X.; Shi, Y.; Sheng, J.; Wang, F. A novel hyaluronidase produced by Bacillus sp. A50. PLoS One 2014, 9, e94156.

21. Hovingh, P.; Linker, A. Hyaluronidase activity in leeches (Hirudinea). Comparative Biochemistry and Physiology Part B: Biochemistry and Molecular Biology 1999, 124, 319-326.

22. Elson, L.A.; Morgan, W.T.J. A colorimetric method for the determination of glucosamine and chondrosamine. Biochemical Journal 1933, 27, 1824-1828.

23. Takahashi, T.; Ikegami-Kawai, M.; Okuda, R.; Suzuki, K. A fluorimetric Morgan-Elson assay method for hyaluronidase activity. Analytical biochemistry 2003, 322, 257-263.

24. Guntenhöner, M.W.; Pogrel, M.A.; Stern, R. A substrate-gel assay for hyaluronidase activity. Matrix 1992, 12, 388-396. 
25. Method for determining the hyaluronidase activity of drugs using lyophilisate lidase as a standard sample, 2018. RU 2649800.

26. Messina, L.; Vaccaro, S.; Caruso, S.; Gennari, G. Extracellular hyaluronidase from Streptomyces koganeiensis, 2012. US Patent App. $13 / 318,476$

27. Pavan, M.; Beninatto, R.; Galesso, D.; Panfilo, S.; Vaccaro, S.; Messina, L.; Guarise, C. A new potential spreading factor: Streptomyces koganeiensis hyaluronidase. A comparative study with bovine testes hyaluronidase and recombinant human hyaluronidase of the HA degradation in ECM. Biochimica et Biophysica Acta (BBA)-General Subjects 2016, 1860, 661-668.

28. LI, M.W.; Yudin, A.I.; Robertson, K.R.; Cherr, G.N.; Overstreet, J.W. Importance of glycosylation and disulfide bonds in hyaluronidase activity of macaque sperm surface PH-20. Journal of andrology 2002, 23, 211-219.

29. Gmachl, M.; Kreil, G. Bee venom hyaluronidase is homologous to a membrane protein of mammalian sperm. Proceedings of the National Academy of Sciences 1993, 90, 3569-3573.

30. Vikha, I.; Sakharovsky, V.; Bystrov, V.; Khorlin, A.Y. A proton magnetic resonance kinetic approach to the stereochemistry of carbohydrate enzymic hydrolysis. Hydrolysis of hyaluronic acid by testicular hyaluronidase. Carbohydrate research 1972, 25, 143-152.

31. Sugahara, K.; Yamada, S.; Sugiura, M.; Takeda, K.; Yuen, R.; Khoo, H.; Poh, C. Identification of the reaction products of the purified hyaluronidase from stonefish (Synanceja horrida) venom. Biochemical Journal 1992, 283, 99-104.

32. Alkrad, J.A.; Mrestani, Y.; Stroehl, D.; Wartewig, S.; Neubert, R. Characterization of enzymatically digested hyaluronic acid using NMR, Raman, IR, and UV-Vis spectroscopies. Journal of pharmaceutical and biomedical analysis 2003, 31, 545-550.

33. Heyraud, A.; Gey, C.; Leonard, C.; Rochas, C.; Girond, S.; Kloareg, B. NMR spectroscopy analysis of oligoguluronates and oligomannuronates prepared by acid or enzymatic hydrolysis of homopolymeric blocks of alginic acid. Application to the determination of the substrate specificity of Haliotis tuberculata alginate lyase. Carbohydrate Research 1996, 289, 11-23.

34. Chernomor, O.; Von Haeseler, A.; Minh, B.Q. Terrace aware data structure for phylogenomic inference from supermatrices. Systematic biology 2016, 65, 997-1008.

35. Letunic, I.; Bork, P. Interactive Tree Of Life (iTOL) v5: an online tool for phylogenetic tree display and annotation. Nucleic Acids Research 2021, [https://academic.oup.com/nar/advance-article-pdf/doi/10.1093/nar/gkab301/37276427/gkab301.pdf]. gkab301, doi:10.1093/nar/gkab301.

36. Buhren, B.A.; Schrumpf, H.; Hoff, N.P.; Bölke, E.; Hilton, S.; Gerber, P.A. Hyaluronidase: from clinical applications to molecular and cellular mechanisms. European journal of medical research 2016, 21, 1-7.

37. Wohlrab, J.; Finke, R.; Franke, W.G.; Wohlrab, A. Efficacy study of hyaluronidase as a diffusion promoter for lidocaine in infiltration analgesia of skin. Plastic and reconstructive surgery 2012, 129, 771e-772e.

38. Moharib, M.M.; Mitra, S. Alkalinized lidocaine and bupivacaine with hyaluronidase for sub-tenon's ophthalmic block. Regional anesthesia and pain medicine 2000, 25, 514-517.

39. Narayanan, R.; Kuppermann, B.D. Hyaluronidase for pharmacologic vitreolysis. Pharmacology and Vitreoretinal Surgery $2009,44,20-25$.

40. Park, T.H.; Seo, S.W.; Kim, J.K.; Chang, C.H. Clinical experience with hyaluronic acid-filler complications. Journal of Plastic, Reconstructive \& Aesthetic Surgery 2011, 64, 892-896.

41. Grand View Research. Hyaluronidase Market Size, Share \& Trends Analysis Report By Type (Animal-derived, Synthetic), By Application (Dermatology, Chemotherapy, Ophthalmology, Plastic Surgery), By Region And Segment Forecasts, 2019-2026, 2019, [https://www.grandviewresearch.com/industry-analysis/hyaluronidase-market].

42. Ponomareva, T.; Timchenko, M.; Filippov, M.; Lapaev, S.; Sogorin, E. Prospects of Red King Crab Hepatopancreas Processing: Fundamental and Applied Biochemistry. Recycling 2021, 6, 3 . 